\title{
Metastasectomy in Advanced Renal Cell Carcinoma: A Systematic Review
}

\author{
Tala Achkar ${ }^{\mathrm{a}}$, Jodi K. Maranchie ${ }^{\mathrm{b}}$ and Leonard J. Appleman ${ }^{\mathrm{a}, *}$ \\ ${ }^{a}$ Department of Medicine, University of Pittsburgh, School of Medicine, Division of Hematology/ \\ Oncology, Pittsburgh PA, USA \\ ${ }^{\mathrm{b}}$ Department of Urology, University of Pittsburgh School of Medicine, Pittsburgh PA, USA
}

Received 27 August 2018

Accepted 21 November 2018

\begin{abstract}
.
Introduction: Metastasectomy for advanced renal cell carcinoma has been practiced for over 80 years. However, there is uncertainty regarding the clinical benefit of this procedure and the optimum selection of appropriate patients.

Materials and Methods: A systematic literature search was conducted according to the PRISMA statement to identify studies that reported outcomes in patients who underwent metastasectomy at any time. Primary endpoints were overall and disease-free survival. Radiation therapy studies were not included. Case reports and series with less than 20 patients were not included.

Results: Forty-four studies were identified that met the criteria for inclusion, with a total of 4195 patients. No studies that randomized patients to surgery versus no surgery were identified. Disease-free interval, number of metastatic sites and completeness of resection were prognostic for overall survival in many of the included studies. Seventeen studies included patients with lung metastases only (1465 patients in total).

Conclusions: Case series have documented patients with prolonged disease-free interval and survival after metastasectomy. However, without randomized data, the impact of metastasectomy on outcomes in patients with metastatic renal cell carcinoma (mRCC) remains unknown, especially in the evolving landscape of systemic therapies.
\end{abstract}

Keywords: Renal cell carcinoma, metastasectomy

\section{INTRODUCTION}

\section{Metastasectomy in solid tumors}

Traditional oncology teaching holds that metastatic solid tumors represent a broader systemic disease process in which distant micrometastatic deposits will ultimately progress after resection of detectable disease. However, reports of favorable outcomes including prolonged disease-free interval

${ }^{*}$ Correspondence to: Leonard J. Appleman MD, PhD, Department of Medicine, University of Pittsburgh, School of Medicine, Division of Hematology/Oncology 5115 Centre Avenue, Pittsburgh PA 15232, USA, Tel.: +1 617543 7763; Fax: +1 412648 6579; E-mail: applemanlj@upmc.edu. have been reported across tumor types, primarily in retrospective series and case reports. These cases tended to be highly selected and enriched for patients with oligometastatic disease, slow progression, extended disease-free interval, or excellent functional status. Unfortunately, randomized data addressing whether there is a benefit from surgery are lacking. One study conducted at MD Anderson randomized patients with non-small cell lung cancer to consolidation local therapy (surgery or stereotactic radiosurgery) [1] after initial chemotherapy, versus maintenance chemotherapy alone. Local therapy was associated with improved disease-free survival suggesting that the traditional paradigm may be incomplete. A randomized phase 
II study in patients with oligometastatic prostate cancer found improved androgen deprivation-free survival with metastasis-directed therapy (surgery or radiation versus observation) [2]. Aside from these recently published examples, metastasectomy for solid tumors remains based on single-armed case series and physician experience.

\section{Metastasectomy for $m R C C$}

Renal cell carcinoma (RCC) can metastasize to many different organs and has a variable natural history. It may be rapidly progressive or indolent, requiring no immediate systemic treatment [3]. Identifiable metastases are present at diagnosis in up to $30 \%$ of cases or become apparent years after nephrectomy for clinically localized disease in nearly $40 \%$ of cases. The most common site of metastasis is the lung $(45.2 \%)$, followed by bone (29.5\%), lymph nodes (21.8\%), and liver (20.3\%) [4]. Several clinical factors have been associated with improved response to treatment of metastatic RCC (mRCC). These are important in determining suitability for surgical intervention and include performance status, length of disease-free interval, synchronous or metachronous metastasis, burden of metastatic disease and number of location and sites involved [5]. Although there have been many advances in the treatment of mRCC, including the development and approval of immunotherapy regimens, complete responses are still rare. As such, surgical management of metastatic disease remains an important aspect of therapy for long-term disease control.

Metastasectomy for RCC was first reported by Barney and Churchill in 1939 [6]. There have been no randomized controlled trials to address the role of metastasectomy in $\mathrm{mRCC}$, however, there have been many retrospective studies and a few prospective series. This systematic review will summarize and discuss the available evidence.

\section{MATERIALS AND METHODS}

A systematic literature search was conducted according to the PRISMA statement [7] to identify studies reporting outcomes in patients who underwent surgical resection for mRCC. The search was not restricted to a particular time period. The PubMed database was searched using the search the terms "metastasectomy", "surgery", "renal cell carcinoma", "kidney cancer", "pancreas", "bone", "thyroid", and "brain". General internet search engines were also queried using these terms, as was the ASCO Abstract library. All citations were reviewed and evaluated for study design, quality of execution and relevance.

\section{RESULTS}

A search of electronic databases was performed to identify reports of patients who had undergone metastasectomy for mRCC. The initial PubMed search using the terms "metastasectomy" AND "renal cell carcinoma" OR "kidney cancer" identified 329 references. Additional references were identified using the organ-specific terms such as "pancreas" or "bone", including qualifying studies that did not appear in the initial search. Original, prospective and retrospective studies of patients who underwent metastasectomy for mRCC were identified. Additional studies were identified by manual review of references contained within the reports and review articles from the initial PubMed search. Case reports and series with fewer than 20 cases were excluded. Forty-four studies were ultimately included in the analysis. Table 1 summarizes the findings reported in these studies, which included a total of 4195 patients. One study in this table, an analysis of 1976 records in the National Cancer Database, was not included in this numerical total [8]. Baseline information included in these publications generally included demographics, as well as oncologic features and treatment history, including disease-free interval (DFI) from prior nephrectomy, number of metastatic sites, presence of lymph nodes, organ site of metastases, and whether resection was complete or incomplete. Overall survival was reported as a landmark data point at 1 to 10 years and also as a median value in most of the series. A smaller subset of the studies provided outcomes on disease-free survival (DFS). The length of follow up was reported in 14 studies. No randomized studies of metastasectomy versus no surgery for RCC were identified. However, several papers compared metastasectomy patients to matched controls who did not undergo surgery. There was considerable heterogeneity in the reporting of outcomes among the studies. Most reported an analysis of risk factors for outcomes, generally overall survival. Twenty two of 44 studies included a multivariate analysis. Some of the studies were limited to metastases to individual organ sites: these data are discussed below, and denoted in Table 1. 
Table 1

Studies of metastasectomy in mRCC. The 44 studies that were met criteria for inclusion in this systematic review are here. NA = not available; Multi $=$ Multiple sites

\begin{tabular}{|c|c|c|c|c|c|c|c|c|c|}
\hline Study & Years & $\mathrm{N}^{*}$ & Comparitor & $\begin{array}{l}\text { Follow-up months: } \\
\text { median (range) }\end{array}$ & $\begin{array}{l}\text { mDFS } \\
\text { (months }\end{array}$ & $\begin{array}{c}\text { Median } \\
\text { OS }\end{array}$ & $\begin{array}{l}5 \text { year } \\
\text { OS }(\%)\end{array}$ & Organ & Ref. \\
\hline Jett 1983 & 1970-1979 & 44 & None & NA & NA & 33 & 27 & Lung & [47] \\
\hline Cerfolio 1992 & 1965-1989 & 96 & None & $36(2-280)$ & NA & 38 & 35.9 & Lung & [48] \\
\hline Pogrebniak 1992 & $1985-1991$ & 23 & None & NA & NA & 43 & NA & Lung & [49] \\
\hline Kierney 1994 & 1970-1990 & 41 & None & 38 & NA & 41 & 31 & Multi & [50] \\
\hline Althausen 1997 & 1977-1996 & 38 & None & NA & NA & 72 & 55 & Bone & [16] \\
\hline Fourquier 1997 & 1960-1994 & 50 & None & $42(1-200)$ & NA & NA & 44 & Lung & [51] \\
\hline Kavolius 1998 & 1980-1993 & 211 & None & NA & NA & NA & 44 & Multi & [52] \\
\hline Friedel 1999 & 1980-1995 & 77 & Nonre & NA & NA & NS & 39 & Lung & [53] \\
\hline Piltz 2002 & $1980-2000$ & 105 & None & NA & NA & 43 & 40 & Lung & [54] \\
\hline Pfannschmidt 2002 & $1985-1999$ & 191 & None & $21.4(0.1-157.8)$ & NA & NA & 36.9 & Lung & [11] \\
\hline Hofmann 2005 & $1975-2003$ & 64 & None & NA & NA & 39.2 & 33 & Lung & [55] \\
\hline Murthy 2005 & 1986-2001 & 92 & None & NA & NA & NA & 31 & Lung & [56] \\
\hline Marulli 2006 & 1988-2004 & 59 & None & NA & NA & NA & 53 & Lung & [57] \\
\hline Assaoud 2007 & 1984-2005 & 65 & No & NA & NA & NA & 34.4 & Lung & [58] \\
\hline Kwak 2007 & 1990-2004 & 21 & No surgery $(n=41)$ & NA & NA & 36.5 & 47.6 & Multi & [59] \\
\hline Lin 2008 & 1974-2004 & 295 & None & NA & NA & NA & 11 & Bone & [15] \\
\hline Thelen 2007 & 1988-2007 & 31 & None & $29(1-185)$ & 27 & 48 & 38.9 & Liver & [20] \\
\hline Eggner 2008 & 1989-2007 & 44 & No surgery $(n=85)$ & NA & NA & 45 & 49 & Multi & [60] \\
\hline Iesalnieks 2008 & 1983-2007 & 45 & None & NA & NA & 71 & 51 & Thyroid & [61] \\
\hline Zerbi 2008 & 1998-2006 & 23 & No surgery $(n=13)$ & NA & 44 & NA & $88 \%$ & Pancreas & [62] \\
\hline Daliani 2009 & 1991-1999 & 38 & None & NA & 21.6 & 56.4 & NA & Multi & [45] \\
\hline Alt 2011 & 1976-2006 & 382 & No surgery (505) & NA & NA & NA & NA & Multi & [10] \\
\hline Kanzaki 2011 & $1973-2008$ & 48 & None & $39(3-177)$ & NA & $\mathrm{NA}$ & 47 & Lung & [63] \\
\hline Kawashima 2011 & 1998-2008 & 25 & None & NA & 7.4 & 33.9 & 35.5 & Lung & [64] \\
\hline Meimarakis 2011 & 1986-2006 & 202 & None & NA & NA & 39.5 & 39 & Lung & [65] \\
\hline Naito 2011 & 1988-2009 & 556 & None & NA & NA & 80 & 48.9 & Multi & [66] \\
\hline Ruys 2011 & 1990-2008 & 33 & None & NA & 10 & 33 & 43 & Liver & [18] \\
\hline Petralia 2012 & 1999-2008 & 57 & Nephrectomy only $(n=121)$ & $21(1-235)$ & NA & 14 & NA & Multi & [67] \\
\hline Kudelin 2013 & 1999-2009 & 116 & None & NA & NA & 63.4 & 47 & Multi & [13] \\
\hline Tosco $2013^{1}$ & $1998-2011$ & 109 & None & $52.7(1.37-283)$ & NA & 54.7 & 46.9 & Multi & [68] \\
\hline Renaud 2014 & $1993-2011$ & 122 & None & NA & 22.1 & 94 & 66 & Lung & [12] \\
\hline Santoni 2014 & $2005-2014$ & 42 & No surgery & NA & 36.2 & 103 & NA & Pancreas & [24] \\
\hline Untch 2014 & 1993-2012 & 23 & Panc. Met. Other primary & NA & NA & 96 & NA & Pancreas & [23] \\
\hline Baier 2015 & 1996-2012 & 237 & None & $46(2-198)$ & 60 & 69 & $54 \%$ & Lung & [14] \\
\hline Benhaim 2015 & $1997-2012$ & 20 & None & $69(1-150)$ & NA & NA & NA & Pancreas & [22] \\
\hline Du 2015 & 2006-2015 & 33 & No surgery $(n=81)$ & $24.1(16-32)$ & NA & 39.1 & NA & Bone & [17] \\
\hline Yu 2015 & $2004-2013$ & 42 & No surgery $(n=54)$ & 45 & NA & $54 / 16^{2}$ & NA & Multi & [69] \\
\hline Jakubowski 2016 & $1990-2013$ & 172 & None & 36 & 25 & NA & NA & Multi & [70] \\
\hline Thomas $2016^{3}$ & 1986-2011 & 67 & Targeted therapy only $(n=121)$ & NA & NA & $8.4 / 6.2$ & NA & Multi & [71] \\
\hline You 2016 & $2006-2013$ & 61 & No surgery $(n=263)$ & NA & $29.5 / 18.8^{2}$ & $92.5 / 29.6^{2}$ & NA & Multi & [72] \\
\hline Ohtaki 2017 & 1993-2014 & 84 & None & NA & NA & 79.2 & 59.7 & Lung & [73] \\
\hline Verbiest 2018 & $1995-2017$ & 43 & None & NA & 17 & 121 & 73 & Multi & [38] \\
\hline Procopio 2018 & $2012-2018$ & $36 / 32^{4}$ & None & 21 & $35 / 29^{4}$ & NA & NA & Multi & [44] \\
\hline Sun $2018^{5}$ & 2006-2013 & 1976 & No Surgery $(n=5018)$ & NA & NA & 24.1 & NA & Multi & {$[8]$} \\
\hline
\end{tabular}

${ }^{1}$ Cause-specific survival reported. ${ }^{2}$ Complete/incomplete metastasectomy. ${ }^{3}$ Sarcomatoid cases only. OS: synchronous/metachronous. ${ }^{4}$ Observation/sorafenib. ${ }^{5}$ National Cancer Registry Database review. Median OS for postpropensity matched cohort $(n=3390)$.

\section{Lung}

The lung is the most common target organ for metastasis from RCC. Of the 44 studies reviewed here, 17 were comprised of patients who had metastasectomy for RCC lung metastases. These accounted for 1462 out of 4195 total patients included in this systematic review. Prognostic factors for survival with lung metastases have been studied in multi- ple series and meta-analyses. In a systematic review of 16 studies with a total of 1447 patients, Zhou et al. reported $1,3,5$, and 10-year overall survival (OS) rates of $84 \%, 59 \%, 43 \%$, and $20 \%$, respectively following lung metastasectomy [9]. They identified lymph node involvement, incomplete resection, multifocality, size, synchronous metastases, and a short DFI as poor prognostic factors. Another report from the Mayo Clinic detailed 887 patients who underwent 
nephrectomy for RCC and subsequently developed metastatic disease. Of these 125 patients had complete resection of all metastatic disease. Patients who had lung-only disease had a 5-year cancer-specific survival (CSS) of $73.6 \%$ after complete resection compared with $19 \%$ for those without complete resection [10]. Similarly, in a Heidelberg series of 191 patients with pulmonary RCC metastases, 149 patients achieved complete resection [11] for a 5-year OS of $41.5 \%$ compared with $22.1 \%$ without complete resection. Notably, in this series, lymph node involvement decreased the 5-year OS to only $24.4 \%$.

The negative impact of concomitant lymph node involvement was also emphasized by Renaud and colleagues. In their report of 122 patients who underwent pulmonary metastasectomy, 35\% had lymph node involvement, decreasing OS from 107 months to 37 months $(p=0.003)$ [12]. Kudelin and colleagues completely resected all mediastinal lymphadenopathy at the time of pulmonary metastasectomy with overall survival of $49 \%$ and $21 \%$ at 5 and 10 years, respectively [13]. Mediastinal lymph nodes were positive in $46 \%$. Notably, in this series the presence of intra-thoracic lymph node metastases did not result in inferior survival after metastasectomy, suggesting there may be clinical benefit to lymphadenectomy [13].

Finally, Baier and colleagues examined complete resection of multi-focal pulmonary RCC metastases (mean 13/patient). Using laser resection in 237 patients, they achieved complete resection in 208 for a median OS of 69 months compared with 19 months for those with an incomplete resection $(p<0.00001)$ [14]. Although a higher number of metastases was associated with a shorter OS, the advantage of complete resection was maintained for all levels of disease.

In summary, these studies demonstrate the relative safety and feasibility of resection of pulmonary metastasis and the potential for favorable outcomes. The impact of surgery on overall survival, however, is not definitively established by these non-randomized studies.

\section{Bone}

Bone is the second most common site of metastatic disease in RCC. Surgery (both resection and mechanical stabilization) and radiotherapy are often performed to mitigate local complications. Outcomes data in large series, however, are limited. A retrospective study of 295 patients with bone metastases who underwent orthopedic metastasectomy at MD Anderson showed an OS of $47 \%$ and $11 \%$ at 1 year and 5 years, respectively [15]. Another report of patients treated between 1977 and 1996 at Massachusetts General Hospital showed a 5 year OS of $55 \%$ [16]. These results are particularly notable, because they were obtained prior to the development of effective systemic therapies. Both identified a solitary site of bone metastasis as a strong predictor of overall survival. A more recent published series included 33 patients who underwent surgical resection with or without radiation, plus systemic targeted therapy [17]. Median OS was 39.1 months for surgical resection versus 7.6 months for 59 patients with bone metastases who did not undergo surgery. The authors acknowledge the potential for selection bias in these data. The impact of metastasectomy on survival in patients with RCC bone metastases remains unknown without randomized data. However, local disease control for palliation and preservation of function provides a strong clinical rationale for surgery in many cases and would make randomization of these patients to surgery versus no surgery clinically challenging.

\section{Liver}

A retrospective review from 14 centers in the Netherlands identified 33 patients who underwent resection or ablation of liver metastases [18]. The OS at 1,3 , and 5 years was $79 \%, 47 \%$, and $43 \%$ respectively. Metachronous metastases and radical resection were statistically significant prognostic factors. Size $<50 \mathrm{~mm}$, solitary metastases and presence of extrahepatic metastases did not significantly impact survival. Another retrospective study by Staehler et al. identified 88 patients with liver metastases, including 68 who underwent metastasectomy [19]. The 5-year OS after metastasectomy was $62 \%$ compared to $29 \%$ in those who did not have a resection. A retrospective study by Thelen et al. of 31 patients who underwent surgery for liver metastases reported overall survival of $82 \%, 54 \%$ and $39 \%$ at 1,2 and 5 years [20]. Incomplete resection or positive margins emerged as a statistically significant prognostic factor in multivariate analysis.

\section{Pancreas}

Renal cell carcinoma can metastasize to the pancreas, in many cases as the only site of recurrent disease. Published case series are generally small, 
but favorable survival outcomes have been reported. In a series of 19 patients who underwent surgery for pancreatic RCC metastases by Fikatas et al., 5-year OS was $71.4 \%$ [21]. A similar series of 20 patients with pancreatic metastasectomy showed a $72 \%$ OS at 4 years [22]. Consistent with these findings, a study of 27 patients undergoing pancreatic metastasectomy at Memorial Sloan-Kettering Cancer Center found a median OS of 8 years [23]. In contrast, a retrospective study of patients from 16 Italian centers with pancreatic metastases included 44 patients who underwent surgery with or without systemic therapy and 59 patients who had systemic therapy alone [24]. Median OS was 103 months in the patients who underwent surgery and 86 months in those who did not: a difference that was not statistically significant. MSKCC prognostic group was predictive of overall survival. Median overall survival was not reached in the good risk group; 86 months in the intermediate risk group and 42 months in the poor risk group. The authors conclude that outcomes are favorable in patients with pancreatic RCC metastases, and that pancreatic resection did not improve survival. Taken together, these studies suggest that patients with pancreatic metastases of RCC generally have an indolent course and favorable prognosis.

\section{Brain}

Brain metastases from RCC can cause devastating neurological complications. Therefore, these cases are generally treated promptly with stereotactic radiosurgery (SRS), whole brain radiation, or surgical resection. A series from MD Anderson of patients treated with SRS observed a median OS of 4-11 months after diagnosis with a 5-year OS of $12 \%$ [25]. Large surgical series were not identified in the literature. Local control of brain disease remains an objective of the highest priority regardless of impact on overall disease status, owing to the critical importance of preserving CNS function.

\section{“Atypical” Metastases}

In a study which defined "atypical" sites of metastasis as those that did not occur in the thorax, bone, liver, brain or adrenal, 37 patients who had "atypical" metastasectomy were compared to 57 patients who had lung metastasectomy. The authors reported that those who underwent atypical metastasectomy had a median overall survival of 40.8 months, whereas those who underwent lung metastasectomy had a median overall survival of 50.7 months $(p=0.372)$ [26].

\section{Prognostic factors}

Most of the studies included in this review attempted to identify prognostic factors associated with favorable outcomes after metastasectomy. Univariate and multivariate analysis of prognostic factors for overall survival are summarized in Table 2. Variables that were only evaluated in a minority of the studies were not included in the table. Some of these excluded variables, such as tumor size and MSKCC or IMDC risk score, were associated with survival in individual studies. In general, solitary or oligometastatic disease, metachronous metastasis with a disease-free interval of $>2$ years, complete resection, and absence of lymph node involvement are associated with favorable outcome after metastasectomy $[27,28]$.

\section{DISCUSSION}

Although metastasectomy was first reported for advanced renal cell carcinoma almost 80 years ago [6], there have still been no randomized studies addressing the potential benefit of this procedure. Many retrospective series have been reported, some of which have incorporated case-control comparisons to matched patients who did not undergo surgery. These case series are small to moderate in size, but a number of systematic reviews and metaanalyses have pooled the data from selected series into larger data sets. Zaid et al. analyzed 8 cohort studies with a total of 2,267 patients who underwent metastasectomy [29]. Median OS ranged from 36.5 to 142 months in those who underwent complete metastasectomy compared to 8.4 to 27 months for incomplete metastasectomy. Complete metastasectomy was independently associated with a reduction in mortality. Similar conclusions were reached in a systematic review of patients who underwent local therapies for mRCC including metastasectomy and radiation therapy: examination of 16 studies in detail suggested that complete metastasectomy was associated with greater survival versus incomplete or no surgery [2]. A large retrospective study using the National Cancer Database identified 6994 mRCC patients, 1976 of whom underwent metastasectomy [8]. Patients who underwent metastasectomy had an improved OS compared to those who did not (HR $0.83 ; p<0.001)$. This improvement was seen in the 
Table 2

Clinical variables that were most likely to be associated with overall survival. Studies that examined the relationship between clinical variable and overall survival were included. The most common variables associated with overall survival are shown. Additional variables are examined in the individual publications. $\mathrm{NA}=$ not available. $\mathrm{NS}=$ not significant

\begin{tabular}{|c|c|c|c|c|c|c|c|c|}
\hline & $\mathrm{N}$ & Organ & $\begin{array}{c}\text { Multi/Univariate } \\
\text { analysis }\end{array}$ & $\begin{array}{l}\text { Extent of } \\
\text { resection }\end{array}$ & $\begin{array}{l}\text { Synchronous/ } \\
\text { Metachronous }\end{array}$ & $\begin{array}{l}\text { Disease-Free } \\
\text { Interval } \\
\end{array}$ & $\begin{array}{l}\text { Number of } \\
\text { sites }\end{array}$ & $\begin{array}{c}\text { Nodal } \\
\text { involvement }\end{array}$ \\
\hline Jett 1983 & 44 & Lung & Univariate & NS & NA & $p=<0.05$ & NS & NA \\
\hline Cerfolio 1992 & 96 & Lung & Univariate & NA & NA & $p=<0.01$ & $p=<0.05$ & NA \\
\hline Pogrebniak 1992 & 23 & Lung & Univariate & $p=0.02$ & NS & NS & NS & NA \\
\hline Kierney 1994 & 41 & Multi & Univariate & NA & NA & NS & NS & NA \\
\hline Althausen 1997 & 38 & Bone & Univariate & NA & NA & $p=0.0007$ & $p=0.05$ & NA \\
\hline Fourquier 1997 & 50 & Lung & Univariate & $p=0.2$ & NS & NS & NS & NS \\
\hline Kavolius 1998 & 211 & Multi & Multivariate & $p=<0.09$ & NA & $p=<0.0001$ & $p=<0.001$ & NA \\
\hline Piltz 2002 & 105 & Lung & Univariate & $p=<0.0001$ & NA & NS & $p=0.029$ & $p=<0.001$ \\
\hline Pfannschmidt 2002 & 191 & Lung & Multivariate & $p=0.049$ & $p=0.028$ & $p=0.012$ & $p=0.002$ & $p=0.0038$ \\
\hline Hofmann 2005 & 64 & Lung & Multivariate & $p=0.001$ & $p=0.033$ & $p=0.005$ & $p=0.02$ & NA \\
\hline Murthy 2005 & 92 & Lung & Multivariate & $p<0.0001$ & NA & $p=0.03$ & NA & $p=0.02$ \\
\hline Marulli 2006 & 59 & Lung & Multivariate & NS & NA & NS & NS & NA \\
\hline Assaoud 2007 & 65 & Lung & Multivariate & NS & NA & $p=0.14$ & NA & $p=0.0018$ \\
\hline Kwak 2007 & 21 & Multi & Multivariate & NA & NA & $p=0.159$ & $p=0.166$ & NA \\
\hline Lin 2007 & 295 & Bone & Univeriate & $p=.52$ & NA & NA & $p<0.0001$ & NA \\
\hline Thelen 2007 & 31 & Liver & Multivariate & $p=0.005$ & NA & $p=0.012$ & & \\
\hline Daliani 2009 & 38 & Multi & Multivariate & $p<0.0001$ & NS & NS & NS & NS \\
\hline Alt 2011 & 392 & Multi & Multivariate & $p=0.001$ & NA & $p=0.001$ & 0.86 & NA \\
\hline Kanzaki 2011 & 48 & Lung & Multivariate & $p=0.034$ & NS & $p=0.009$ & NS & NS \\
\hline Kawashima 2011 & 25 & Lung & Multivariate & $p=0.004$ & NA & NA & NS & NA \\
\hline Meimarakis 2011 & 202 & Lung & Multivariate & $p<0.001$ & $p=0.009$ & $p=0.010$ & $p=0.011$ & $p=0.002$ \\
\hline Naito 2011 & 556 & Multi & Multivariate & $p=0.001$ & NS & NS & NS & NS \\
\hline Ruys 2011 & 33 & Liver & Univariate & $p=<0.001$ & $p=0.03$ & $p=0.051$ & $p=0.93$ & NA \\
\hline Petralia 2012 & 57 & Multi & Multivariate & $p=0.02$ & NA & NA & $p<0.001$ & NA \\
\hline Kudelin 2013 & 116 & Multi & Multivariate & NS & NA & NS & NS & NS \\
\hline Tosco 2013 & 109 & Multi & Multivariate & $p=0.0002$ & $p=0.63$ & $p=0.058$ & NA & NA \\
\hline Renaud 2014 & 122 & Lung & Multivariate & NA & NA & $p=0.02$ & $p=0.34$ & $p=0.01$ \\
\hline Baier 2015 & 237 & Lung & Multivariate & $p=<0.0001$ & $p=0.14$ & $p=0.71$ & $p=0.0029$ & $p=0.34$ \\
\hline Yu 2015 & 42 & Multi & Multivariate & $p=0.033$ & NA & $p=0.003$ & NA & NA \\
\hline Jakubowski $2016^{1}$ & 172 & Multi & Univariate & $p=0.003$ & $p=0.02$ & $p=0.023$ & NA & NA \\
\hline Thomas 2016 & 67 & Multi & Multivariate & NS & NS & NS & NS & $p=0.03$ \\
\hline You 2016 & 61 & Multi & Multivariate & NA & NA & NA & $p<0.001$ & NA \\
\hline Ohtaki 2017 & 84 & Lung & Multivariate & $p=0.015$ & NA & NA & NS & NS \\
\hline
\end{tabular}

${ }^{1}$ Recurrence-free survival.

patients who received targeted therapy (HR 0.77; $p=0.008)$. Although multivariate analysis was performed to account for confounding factors in the systematic reviews and some of the primary series, the possibility of unseen confounders limits the strength of the conclusions that can be drawn regarding the benefit of surgery. The association between metastasectomy and longer OS could be explained by unmeasured enrichment for favorable disease biology or host characteristics in patients selected by their physicians for surgery [27].

In spite of the shortcomings in the available data, expert panels have recommended that metastasectomy be considered in selected cases of mRCC. The National Comprehensive Cancer Network (NCCN) guidelines recommend metastasectomy as an option for patient with oligometastatic clear cell or non-clear cell disease [30]. The ESMO clinical practice guidelines recommend consideration of metastatectomy or radiation therapy patients with mRCC after multidisciplinary review: particularly patients with oligometastatic disease, disease-free interval greater than 2 years, complete surgical resection, low pathologic grade and disease control through systemic therapy [31].

\section{Cytoreductive nephrectomy: A paradigm for the study of metastasectomy}

While there have been no randomized trials evaluating metastasectomy for RCC, studies of cytoreductive nephrectomy demonstrate the feasibility randomizing patients to surgery in a similar population: two studies published independently in 2001 by the SWOG and EORTC cooperative groups demonstrated an overall survival benefit to cytore- 
ductive nephrectomy followed by interferon $\alpha-2 b$ versus interferon alone $[32,33]$. A combined analysis of the studies found a $31 \%$ reduction in the risk of death associated with surgery [34] and cytoreductive nephrectomy has been incorportated into the standard of care. Since that time, however, systemic therepy for mRCC has shifted away from interferon to targeted therapies such as sunitinib, introducing uncertainty regarding the role of cytoreductive nephrectomy. To address this question, the CARMENA study randomized patients to standard of care cytoredutive nephrectomy followed by sunitinib vs sunitinib alone. The study found that sunitinib alone was non-inferior to cytoreductive nephrectomy followed by sunitinib [35]. The SWOG, EORTC and CARMENA studies of cytoreductive nephrectomy serve as a paradigm for potential randomized studies of metastasectomy in the appropriate setting.

\section{Patient selection}

Although disease-free interval, number of metastases and other factors have been associated with favorable outcomes after metastasectomy, there are no clear guidelines for selecting which patients will benefit from surgery. The MSKCC and IMDC instruments provide prognostic information for patients with $\mathrm{mRCC}$ based on readily available clinical data $[36,37]$. In some of the studies covered by this retrospective review, MSKCC or IMDC risk group was prognostic for outcome following metastasectomy. However, these data are prognostic, and are not predictive for benefit from surgery. In recent years, the molecular characteristics of cancers have been added to these clinical features for both prognosis and prediction of benefit from particular therapies. In order to identify a molecular signature predictive of favorable outcome after metastasectomy in mRCC, Verbiest et al. performed a retrospective study of molecular tumor subtypes $43 \mathrm{mRCC}$ patients who underwent complete metastasectomy, [38]. Four molecular subtypes in the metastatic setting were identified that differed in terms of mRNA expression, methylation status, mutation profile, cytogenetic abnormalities, and immune infiltration [39, 40]. The subtypes (ccrcc1-4) differed in their OS and also response rate and PFS on the angiogenesis inhibitors sunitinib and pazopanib. Patients with ccrcc1 or ccrce4 tumors were at a higher risk of relapse after complete metastasectomy, whereas patients with a ccrcc 2 or ccrcc3 tumor usually experienced a long DFS [38]. As our understanding of the molecular features of
RCC improves, there is the potential for additional predictive models for metastasectomy in addition to particular systemic therapies.

\section{Perioperative systemic therapy and metastasectomy}

Adjuvant systemic therapy after nephrectomy for non-metastatic RCC has been studied in a number of randomized trials over the past 3 decades, and sunitinib was FDA approved for high risk, nonmetastatic RCC based on the results of the S-TRAC study [41]. The optimal adjuvant therapy following nephrectomy remains under evaluation [42], and randomized studies of several anti-PD-1 checkpoint inhibitors are underway. An analogous question regarding the benefit of systemic therapy arises after complete metastasectomy with no evidence of disease (NED) post-operatively. A number of completed and ongoing studies have examined this question. The Cytokine Working Group conducted a randomized study of a single cycle of high dose interleukin-2 vs. observation for high risk patients after nephrectomy for RCC [43]. The study also included a separate cohort of 25 patients who were status post metastasectomy with NED. The study did not meet its endpoint of improvement in disease-free survival. The randomized phase II RESORT trial assigned patients who were NED after metastasectomy to 52 weeks of sorafenib treatment versus placebo [44]. The study was closed before planned accrual was complete, and the primary endpoint of improvement in recurrence-free survival with sorafenib was not reached. More than half the patients were free of recurrent disease at 24 months; while not randomized to no surgery, these prospectively enrolled and monitored subjects provide a unique high-quality data set regarding outcomes after metastasectomy. The integration of systemic therapy and metastasectomy was also addressed by Daliani, Jonasch et al., who published a prospective study of patients who underwent metastasectomy after systemic therapy (generally a cytokine based treatment with or with 5-fluorouracil) and were followed by post-operative systemic therapy of a similar nature [45]. Median PFS was 21.6 months, and median OS was 56.4 months.

There are additional randomized trials currently underway, one of which is studying adjuvant pazopanib versus placebo (NCT01575548) and another is a phase II trial of adjuvant sunitinib following resection of pulmonary metastases (NCT01216371). Ongoing adjuvant studies of 
PD-1 and PD-L1 antibody checkpoint inhibitors are including patients with completely resected small volume synchronous metastatic disease (pembrolizumab-NCT03142334, atezolizumabNCT03024996). Pre-clinical data support the hypothesis that a minimum volume of disease is required for maximum anti-PD-1 checkpoint inhibitor activity [46]. This paradigm is being evaluated in the PROSPER-RCC randomized study of nivolumab prior to and following surgery for high risk disease (NCT03055013).

\section{CONCLUSION}

Metastasectomy has been employed in the care of patients with mRCC for many decades, although the clinical benefit is based primarily on retrospective, non-randomized series. Selection of appropriate patients must currently rely on the physician's experience, as well as retrospective analyses suggesting that factors such as disease-free interval and number of metastases are associated with favorable survival. The utility of metastasectomy must be evaluated in the setting of available systemic therapy, which has been evolving at an accelerating pace. Historical data must be considered in light of this shifting landscape. Randomized studies would be highly informative, but are subject to the same concerns.

\section{CONFLICT OF INTEREST}

Leonard J. Appleman: Research funding to Institution: BMS, Calithera, Merck, Peleton, Seattle Genetics.

Jodi Maranchie: None

Tala Achkar: None.

\section{REFERENCES}

[1] Gomez DR, Blumenschein GR Jr, Lee JJ, Hernandez M, Ye R, Camidge DR, et al. Local consolidative therapy versus maintenance therapy or observation for patients with oligometastatic non-small-cell lung cancer without progression after first-line systemic therapy: A multicentre, randomised, controlled, phase 2 study. The Lancet Oncology. 2016;17(12):1672-82.

[2] Dabestani S, Marconi L, Hofmann F, Stewart F, Lam TB, Canfield SE, et al. Local treatments for metastases of renal cell carcinoma: A systematic review. The Lancet Oncology. 2014;15(12):e549-61.

[3] Rini BI, Dorff TB, Elson P, Rodriguez CS, Shepard D, Wood L, et al. Active surveillance in metastatic renal-cell carcinoma: A prospective, phase 2 trial. The Lancet Oncology. 2016;17(9):1317-24.
[4] Bianchi M, Sun M, Jeldres C, Shariat SF, Trinh QD, Briganti A, et al. Distribution of metastatic sites in renal cell carcinoma: A population-based analysis. Ann Oncol. 2012;23(4):973-80.

[5] Leibovich BC, Cheville JC, Lohse CM, Zincke H, Frank I, Kwon ED, et al. A scoring algorithm to predict survival for patients with metastatic clear cell renal cell carcinoma: A stratification tool for prospective clinical trials. J Urol. 2005; 174(5):1759-63; discussion 63.

[6] Barney J, Churchill E. Adenocarcinoma of the kidney with metastasis to the lung: Cured by nephrectomy and lobectomy. J Urol. 1939;42:269.

[7] Moher D, Shamseer L, Clarke M, Ghersi D, Liberati A, Petticrew M, et al. Preferred reporting items for systematic review and meta-analysis protocols (PRISMA-P) 2015 statement. Systematic Reviews. 2015;4(1):1.

[8] Sun M, Meyer CP, Karam JA, de Velasco G, Chang SL, Pal SK, et al. Predictors, utilization patterns, and overall survival of patients undergoing metastasectomy for metastatic renal cell carcinoma in the era of targeted therapy. Eur J Surg Oncol. 2018.

[9] Zhao Y, Li J, Li C, Fan J, Liu L. Prognostic factors for overall survival after lung metastasectomy in renal cell cancer patients: A systematic review and meta-analysis. Int J Surg. 2017;41:70-7.

[10] Alt AL, Boorjian SA, Lohse CM, Costello BA, Leibovich BC, Blute ML. Survival after complete surgical resection of multiple metastases from renal cell carcinoma. Cancer. 2011;117(13):2873-82.

[11] Pfannschmidt J, Hoffmann H, Muley T, Krysa S, Trainer C, Dienemann H. Prognostic factors for survival after pulmonary resection of metastatic renal cell carcinoma. Ann Thorac Surg. 2002;74(5):1653-7.

[12] Renaud S, Falcoz PE, Alifano M, Olland A, Magdeleinat $\mathrm{P}$, Pages $\mathrm{O}$, et al. Systematic lymph node dissection in lung metastasectomy of renal cell carcinoma: An 18 years of experience. J Surg Oncol. 2014;109(8):823-9.

[13] Kudelin N, Bolukbas S, Eberlein M, Schirren J. Metastasectomy with standardized lymph node dissection for metastatic renal cell carcinoma: An 11-year single-center experience. Ann Thorac Surg. 2013;96(1):265-70: discussion 70-1.

[14] Baier B, Kern A, Kaderali L, Bis B, Koschel D, Rolle A. Retrospective survival analysis of 237 consecutive patients with multiple pulmonary metastases from advanced renal cell carcinoma exclusively resected by a $1318-\mathrm{nm}$ laser. Interactive Cardiovascular and Thoracic Surgery. 2015;21(2):211-7.

[15] Lin PP, Mirza AN, Lewis VO, Cannon CP, Tu SM, Tannir NM, et al. Patient survival after surgery for osseous metastases from renal cell carcinoma. The Journal of Bone and Joint Surgery American Volume. 2007;89(8):1794-801.

[16] Althausen P, Althausen A, Jennings LC, Mankin HJ. Prognostic factors and surgical treatment of osseous metastases secondary to renal cell carcinoma. Cancer. 1997;80(6):1103-9.

[17] Du Y, Pahernik S, Hadaschik B, Teber D, Duensing S, Jager $\mathrm{D}$, et al. Survival and prognostic factors of patients with renal cell cancer with bone metastasis in the era of targeted therapy: A single-institution analysis. Urol Oncol. 2016;34(10):433.e1-8.

[18] Ruys AT, Tanis PJ, Nagtegaal ID, van Duijvendijk P, Verhoef $\mathrm{C}$, Porte RJ, et al. Surgical treatment of renal cell cancer liver metastases: A population-based study. Annals of Surgical Oncology. 2011;18(7):1932-8. 
[19] Staehler MD, Kruse J, Haseke N, Stadler T, Roosen A, Karl A, et al. Liver resection for metastatic disease prolongs survival in renal cell carcinoma: 12-year results from a retrospective comparative analysis. World J Urol. 2010;28(4):543-7.

[20] Thelen A, Jonas S, Benckert C, Lopez-Hanninen E, Rudolph $B$, Neumann $\mathrm{U}$, et al. Liver resection for metastases from renal cell carcinoma. World J Surg. 2007;31(4): 802-7.

[21] Fikatas P, Klein F, Andreou A, Schmuck RB, Pratschke J, Bahra M. Long-term Survival After Surgical Treatment of Renal Cell Carcinoma Metastasis Within the Pancreas. Anticancer Res. 2016;36(8):4273-8.

[22] Benhaim R, Oussoultzoglou E, Saeedi Y, Mouracade P, Bachellier P, Lang H. Pancreatic metastasis from clear cell renal cell carcinoma: Outcome of an aggressive approach. Urology. 2015;85(1):135-40.

[23] Untch BR, Allen PJ. Pancreatic metastasectomy: The Memorial Sloan-Kettering experience and a review of the literature. J Surg Oncol. 2014;109(1):28-30.

[24] Santoni M, Conti A, Partelli S, Porta C, Sternberg CN, Procopio $\mathrm{G}$, et al. Surgical resection does not improve survival in patients with renal metastases to the pancreas in the era of tyrosine kinase inhibitors. Annals of Surgical Oncology. 2015;22(6):2094-100.

[25] Wronski M, Maor MH, Davis BJ, Sawaya R, Levin VA. External radiation of brain metastases from renal carcinoma: A retrospective study of 119 patients from the M. D. Anderson Cancer Center. Int J Radiat Oncol Biol Phys. 1997;37(4):753-9.

[26] Antonelli A, Arrighi N, Corti S, Legramanti S, Zanotelli T, Cozzoli A, et al. Surgical treatment of atypical metastasis from renal cell carcinoma (RCC). BJU Int. 2012;110(11 Pt B):E559-63

[27] Bex A. Integrating metastasectomy and stereotactic radiosurgery in the treatment of metastatic renal cell carcinoma. EJC Suppl. 2013;11(2):192-203.

[28] Bolukbas S, Kudelin N, Eberlein M, Fisseler-Eckhoff A, Schirren J. The influence of the primary tumor on the longterm results of pulmonary metastasectomy for metastatic renal cell carcinoma. The Thoracic and Cardiovascular Surgeon. 2012;60(6):390-7.

[29] Zaid HB, Parker WP, Safdar NS, Gershman B, Erwin PJ, Murad MH, et al. Outcomes Following Complete Surgical Metastasectomy for Patients with Metastatic Renal Cell Carcinoma: A Systematic Review and Meta-Analysis. J Urol. 2017;197(1):44-9.

[30] National Comprehensive Cancer Network: Kidney Cancer (Version 2.2019) [Internet]. 2018 [cited November 18, 2018]. Available from: https://www.nccn.org/professionals/ physician_gls/pdf/kidney.pdf

[31] Escudier B, Porta C, Schmidinger M, Rioux-Leclercq N, Bex A, Khoo V, et al. Renal cell carcinoma: ESMO Clinical Practice Guidelines for diagnosis, treatment and follow-up. Annals of Oncology. 2016;27(Supplement 5):v58-v68.

[32] Mickisch GH, Garin A, van Poppel H, de Prijck L, Sylvester R. Radical nephrectomy plus interferon-alfabased immunotherapy compared with interferon alfa alone in metastatic renal-cell carcinoma: A randomised trial. Lancet. 2001;358(9286):966-70.

[33] Flanigan RC, Salmon SE, Blumenstein BA, Bearman SI, Roy V, McGrath PC, et al. Nephrectomy followed by interferon alfa- $2 b$ compared with interferon alfa- $2 b$ alone for metastatic renal-cell cancer. $\mathrm{N}$ Engl $\mathrm{J}$ Med. 2001;345(23):1655-9.
[34] Flanigan RC, Mickisch G, Sylvester R, Tangen C, Van Poppel $\mathrm{H}$, Crawford ED. Cytoreductive nephrectomy in patients with metastatic renal cancer: A combined analysis. J Urol. 2004;171(3):1071-6.

[35] Méjean A, Ravaud A, Thezenas S, Colas S, Beauval J-B, Bensalah K, et al. Sunitinib Alone or after Nephrectomy in Metastatic Renal-Cell Carcinoma. New England Journal of Medicine. 2018;379(5):417-27.

[36] Motzer RJ, Mazumdar M, Bacik J, Berg W, Amsterdam A, Ferrara J. Survival and prognostic stratification of 670 patients with advanced renal cell carcinoma. J Clin Oncol. 1999;17(8):2530-40.

[37] Heng DY, Xie W, Regan MM, Warren MA, Golshayan AR, Sahi C, et al. Prognostic factors for overall survival in patients with metastatic renal cell carcinoma treated with vascular endothelial growth factor-targeted agents: Results from a large, multicenter study. J Clin Oncol. 2009;27(34):5794-9.

[38] Verbiest A, Couchy G, Job S, Caruana L, Lerut E, Oyen R, et al. Molecular Subtypes of Clear-cell Renal Cell Carcinoma are Prognostic for Outcome After Complete Metastasectomy. Eur Urol. 2018.

[39] Brannon AR, Reddy A, Seiler M, Arreola A, Moore DT, Pruthi RS, et al. Molecular Stratification of Clear Cell Renal Cell Carcinoma by Consensus Clustering Reveals Distinct Subtypes and Survival Patterns. Genes Cancer. 2010;1(2):152-63.

[40] Cancer Genome Atlas Research N. Comprehensive molecular characterization of clear cell renal cell carcinoma. Nature. 2013;499(7456):43-9.

[41] Ravaud A, Motzer RJ, Pandha HS, George DJ, Pantuck AJ, Patel A, et al. Adjuvant Sunitinib in High-Risk Renal-Cell Carcinoma after Nephrectomy. N Engl J Med. 2016;375(23):2246-54.

[42] Sun M, Marconi L, Eisen T, Escudier B, Giles RH, Haas NB, et al. Adjuvant Vascular Endothelial Growth Factortargeted Therapy in Renal Cell Carcinoma: A Systematic Review and Pooled Analysis. Eur Urol. 2018.

[43] Clark JI, Atkins MB, Urba WJ, Creech S, Figlin RA, Dutcher JP, et al. Adjuvant high-dose bolus interleukin2 for patients with high-risk renal cell carcinoma: A cytokine working group randomized trial. J Clin Oncol. 2003;21(16):3133-40.

[44] Procopio G, Cognetti F, Miceli R, Milella M, Mosca A, Chiuri V, et al. A randomized, open label, multicenter phase 2 study, to evaluate the efficacy of sorafenib (So) in patients (pts) with metastatic renal cell carcinoma (mRCC) after a radical resection of the metastases: RESORT trial. J Clin Oncol. 2018;36:Suppl; abstr 4502.

[45] Daliani DD, Tannir NM, Papandreou CN, Wang X, Swisher $\mathrm{S}$, Wood CG, et al. Prospective assessment of systemic therapy followed by surgical removal of metastases in selected patients with renal cell carcinoma. BJU Int. 2009; 104(4):456-60.

[46] Liu J, Blake SJ, Yong MC, Harjunpaa H, Ngiow SF, Takeda $\mathrm{K}$, et al. Improved Efficacy of Neoadjuvant Compared to Adjuvant Immunotherapy to Eradicate Metastatic Disease. Cancer Discovery. 2016;6(12):1382-99.

[47] Jett JR, Hollinger CG, Zinsmeister AR, Pairolero PC. Pulmonary resection of metastatic renal cell carcinoma. Chest. 1983;84(4):442-5.

[48] Cerfolio RJ, Allen MS, Deschamps C, Daly RC, Wallrichs SL, Trastek VF, et al. Pulmonary resection of metastatic renal cell carcinoma. Ann Thorac Surg. 1994;57(2): $339-44$. 
[49] Pogrebniak HW, Haas G, Linehan WM, Rosenberg SA, Pass HI. Renal cell carcinoma: Resection of solitary and multiple metastases. Ann Thorac Surg. 1992;54(1):33-8.

[50] Kierney PC, van Heerden JA, Segura JW, Weaver AL. Surgeon's role in the management of solitary renal cell carcinoma metastases occurring subsequent to initial curative nephrectomy: An institutional review. Annals of Surgical Oncology. 1994;1(4):345-52.

[51] Fourquier P, Regnard JF, Rea S, Levi JF, Levasseur P. Lung metastases of renal cell carcinoma: Results of surgical resection. European journal of cardio-thoracic surgery: Official Journal of the European Association for Cardio-Thoracic Surgery. 1997;11(1):17-21.

[52] Kavolius JP, Mastorakos DP, Pavlovich C, Russo P, Burt ME, Brady MS. Resection of metastatic renal cell carcinoma. J Clin Oncol. 1998;16(6):2261-6.

[53] Friedel G, Hurtgen M, Penzenstadler M, Kyriss T, Toomes $\mathrm{H}$. Resection of pulmonary metastases from renal cell carcinoma. Anticancer Res. 1999;19(2c):1593-6.

[54] Piltz S, Meimarakis G, Wichmann MW, Hatz R, Schildberg FW, Fuerst H. Long-term results after pulmonary resection of renal cell carcinoma metastases. Ann Thorac Surg. 2002;73(4):1082-7.

[55] Hofmann HS, Neef H, Krohe K, Andreev P, Silber RE. Prognostic factors and survival after pulmonary resection of metastatic renal cell carcinoma. Eur Urol. 2005;48(1):7781 ; discussion -2 .

[56] Murthy SC, Kim K, Rice TW, Rajeswaran J, Bukowski R, DeCamp MM, et al. Can we predict long-term survival after pulmonary metastasectomy for renal cell carcinoma? Ann Thorac Surg. 2005;79(3):996-1003.

[57] Marulli G, Sartori F, Bassi PF, dal Moro F, Gino Favaretto A, Rea F. Long-term results of surgical management of pulmonary metastases from renal cell carcinoma. The Thoracic and Cardiovascular Surgeon. 2006;54(8):544-7.

[58] Assouad J, Petkova B, Berna P, Dujon A, Foucault C, Riquet M. Renal cell carcinoma lung metastases surgery: Pathologic findings and prognostic factors. Ann Thorac Surg. 2007;84(4):1114-20.

[59] Kwak C, Park YH, Jeong CW, Lee SE, Ku JH. Metastasectomy without systemic therapy in metastatic renal cell carcinoma: Comparison with conservative treatment. Urol Int. 2007;79(2):145-51.

[60] Eggener SE, Yossepowitch O, Kundu S, Motzer RJ, Russo P. Risk score and metastasectomy independently impact prognosis of patients with recurrent renal cell carcinoma. J Urol. 2008;180(3):873-8.

[61] Iesalnieks I, Winter H, Bareck E, Sotiropoulos GC, Goretzki PE, Klinkhammer-Schalke M, et al. Thyroid metastases of renal cell carcinoma: Clinical course in 45 patients undergoing surgery. Assessment of factors affecting patients' survival. Thyroid : Official Journal of the American Thyroid Association. 2008;18(6):615-24.

[62] Zerbi A, Ortolano E, Balzano G, Borri A, Beneduce AA, Di Carlo V. Pancreatic metastasis from renal cell carcinoma: Which patients benefit from surgical resection? Annals of Surgical Oncology. 2008;15(4):1161-8.
[63] Kanzaki R, Higashiyama M, Fujiwara A, Tokunaga T, Maeda J, Okami J, et al. Long-term results of surgical resection for pulmonary metastasis from renal cell carcinoma: A 25-year single-institution experience. European journal of cardio-thoracic surgery : Official Journal of the European Association for Cardio-thoracic Surgery. 2011;39(2): 167-72.

[64] Kawashima A, Nakayama M, Oka D, Sato M, Hatano K, Mukai M, et al. Pulmonary metastasectomy in patients with renal cell carcinoma: A single-institution experience. International Journal of Clinical Oncology. 2011;16(6):660-5.

[65] Meimarakis G, Angele M, Staehler M, Clevert DA, Crispin A, Ruttinger D, et al. Evaluation of a new prognostic score (Munich score) to predict long-term survival after resection of pulmonary renal cell carcinoma metastases. American Journal of Surgery. 2011;202(2):158-67.

[66] Naito S, Kinoshita H, Kondo T, Shinohara N, Kasahara T, Saito K, et al. Prognostic factors of patients with metastatic renal cell carcinoma with removed metastases: A Multicenter Study of 556 patients. Urology. 2013;82(4):846-51.

[67] Petralia G, Roscigno M, Zigeuner R, Strada E, Sozzi F, Da Pozzo L, et al. 450 Complete Metastasectomy is an Independent Predictor of Cancer-Specific Survival in Patients with Clinically Metastatic Renal Cell Carcinoma. European Urology Supplements. 2010;9(2):162.

[68] Tosco L, Van Poppel H, Frea B, Gregoraci G, Joniau S. Survival and impact of clinical prognostic factors in surgically treated metastatic renal cell carcinoma. Eur Urol. 2013;63(4):646-52.

[69] Yu X, Wang B, Li X, Lin G, Zhang C, Yang Y, et al. The Significance of Metastasectomy in Patients with Metastatic Renal Cell Carcinoma in the Era of Targeted Therapy. BioMed Research International. 2015;2015:176373.

[70] Jakubowski CD, Vertosick EA, Untch BR, Sjoberg D, Wei E, Palmer FL, et al. Complete metastasectomy for renal cell carcinoma: Comparison of five solid organ sites. J Surg Oncol. 2016;114(3):375-9.

[71] Thomas AZ, Adibi M, Slack RS, Borregales LD, Merrill MM, Tamboli P, et al. The Role of Metastasectomy in Patients with Renal Cell Carcinoma with Sarcomatoid Dedifferentiation: A Matched Controlled Analysis. J Urol. 2016;196(3):678-84.

[72] You D, Lee C, Jeong IG, Song C, Lee JL, Hong B, et al. Impact of metastasectomy on prognosis in patients treated with targeted therapy for metastatic renal cell carcinoma. Journal of Cancer Research and Clinical Oncology. 2016;142(11):2331-8.

[73] Ohtaki Y, Shimizu K, Aokage K, Nakao M, Yoshida J, Kamiyoshihara M, et al. Histology is a Prognostic Indicator After Pulmonary Metastasectomy from Renal Cell Carcinoma. World J Surg. 2017;41(3):771-9. 